\title{
Food appearances in children's television programmes in Iceland
}

\author{
Steingerdur Olafsdottir ${ }^{1, *}$ and Christina Berg ${ }^{2}$ \\ ${ }^{1}$ School of Education, University of Iceland, Stakkahlid, 105 Reykjavik, Iceland: ${ }^{2}$ Department of Food and Nutrition, \\ and Sport Science, University of Gothenburg, Göteborg, Sweden
}

Submitted 31 January 2017: Final revision received 14 June 2017: Accepted 21 June 2017: First published online 29 August 2017

\begin{abstract}
Objective: Exposure to advertisements cannot fully explain the associations between young children's dietary intake and the time they spend in front of the television. It is therefore of importance to study television content other than advertisements in this aspect. The present study aimed to examine the nature and extent of verbal and visual appearances of foods and beverages in children's television programmes on Icelandic public service television.

Design: A total of $27 \mathrm{~h}$ of children's programmes (domestic and internationally produced) were watched. All verbal and visual appearances of foods and beverages were coded, as well as the context in which the foods/beverages were discussed or appeared.

Setting: Children's programmes on Icelandic public service television.

Subjects: Two food groups were of special interest for their importance from a public health perspective: high-calorie and low-nutrient (HCLN) foods and fruits and vegetables $(\mathrm{F} \& \mathrm{~V})$. The $\chi^{2}$ test and logistic regression were performed to analyse if the occurrence of the two groups was associated with the context where foods/beverages appeared.

Results: Of the 125 different programmes, a food or beverage appeared in $86 \%$. Of the total food appearances ( $n$ 599), HCLN foods accounted for $26 \%$ and F\&V for $23 \%$. HCLN foods were presented as desirable by appearing more frequently with child characters $(P<0 \cdot 01)$ than $\mathrm{F} \& \mathrm{~V}$.

Conclusions: Public service television has the potential to improve the way food and eating is presented in children's programmes, as young childhood is a critical period for founding healthy habits for later life.
\end{abstract}

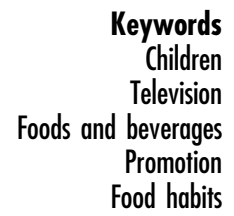

According to a Nordic report ${ }^{(1)}$, unhealthy food habits and overweight are prevalent in Iceland. Among 7- to 12-yearolds, $15 \%$ have an unhealthy diet measured by a dietary index score and the prevalence of overweight (including obesity) is $20 \%$. Epidemiological studies have shown a relationship between higher television watching and children's body weight as well as dietary habits, such as higher intakes of sugary and fast foods and lower intakes of fruits and vegetables ${ }^{(2-7)}$. Even though it is concluded that food commercials largely market non-core foods ${ }^{(8,9)}$, and that there is a causal link between food promotion to children and food consumption ${ }^{(9-11)}$, the exposure to advertisements cannot fully explain the associations between the time young children spend in front of the television and their dietary intake ${ }^{(12)}$. To better understand the influences of television on dietary habits, it is therefore necessary to study other potential influences in addition to the impact of exposure to advertisements.

Folkvord and colleagues ${ }^{(13)}$ have proposed a model for the processes by which exposure to food cues embedded in advertising might influence eating behaviour. According to this model, food cues induce physiological and psychological responses, for example increased salivation and thoughts about foods, that in turn initiate eating (advertising effect process). Over time this leads to a reciprocal relationship between food cue reactivity and the intake of foods considered palatable (incentive sensitization process). This might be the case with food cues other than those in food commercials, such as in children's television programmes or in children's books. Goldman and Descartes ${ }^{(14)}$ have studied food depictions in popular picture books for children and found that unhealthy foods were presented as desirable, possibly increasing the likelihood of children viewing them as desirable.

Research regarding food appearances in television programmes aimed at children is scarce, but warranted, especially in these times of increasing and changing viewing. Children's television programmes, whether they are watched on television or on demand via computer or tablet, are popular among young children. Media statistics 
for Norway, Sweden and Finland from the Nordic Information Centre for Media and Communication Research ${ }^{(15)}$ indicate that television still contributes a substantial share of daily media time. Data for younger children are missing for Iceland but children above 12 years of age and adults spend more than $2 \mathrm{~h}$ watching television daily ${ }^{(16)}$, and reports from the other Nordic countries show that younger children's television time is longer than $1 \mathrm{~h} / \mathrm{d}^{(15)}$.

Studies in other countries have shown that unhealthy food is often present in television programmes aimed at children and adolescents ${ }^{(17,18)}$, that foods in general are more commonly offered and consumed on children's shows than on adult-oriented shows ${ }^{(19)}$, and that unhealthy snacking behaviour ${ }^{(20)}$ and unhealthy foods ${ }^{(17,18)}$ are more often portrayed in shows rated for a youth audience than for adult audiences ${ }^{(20)}$. These studies mostly address commercial channels and not the Nordic countries, but two studies indicate that it is of interest to study children's television programmes also on public service television and in the Nordic countries. A US study ${ }^{(21)}$ found that unhealthy foods appeared to a greater extent than healthy foods on a public service channel, and we observed in a previous study that unhealthy foods were presented in a desirable way for children on Swedish public service television ${ }^{(22)}$. The principle of public service channels is to fulfil society's democratic and cultural needs by, for instance, producing programmes specially intended for children and adolescents, as well as maintaining independence from ideological or economic interests ${ }^{(23)}$.

Due to the public service principle and limited previous research (especially on public service television and outside the USA) on the food content of children's television programmes and the possible influence of this content on the viewer, it is of importance to analyse food appearances in children's television programmes. This is the objective of the current study. More specifically, the study aimed to examine the nature and extent of verbal and visual appearances of foods and beverages in children's programmes on Icelandic public service television, by analysing frequency and type of foods and beverages, determining in what context more or less healthy foods and beverages appear, and identifying messages on health and taste.

\section{Methods}

\section{Sample}

Various children's programmes broadcast in the Icelandic National Broadcasting Service channel (RÚV) were the object of the study. A strategic sampling aimed at representing different days of the week, times of the day and times of the year (different months of autumn and winter), as well as different types of programmes. The sample analysed was aired from October 2013 to April 2014, and from March 2015 to February 2016, excluding Christmas, Easter and summer. A total of $27 \mathrm{~h}$ of children's programmes were watched and coded: domestic and internationally produced children's programmes, cartoons and films, animated and not. The required sample size was estimated based on a previous study on children's television programmes in Sweden ${ }^{(22)}$. A total of 125 different programmes were included in the sample. They ranged in length from 1 to $30 \mathrm{~min}$. The coded material represented every afternoon of the week (a total of $15 \mathrm{~h}$ ) and weekend mornings (a total of $12 \mathrm{~h}$ ), with each month represented.

Advertisements were excluded in the material coded. Advertisements partly finance this state-owned channel (RÚV); however, advertisements are not allowed $5 \mathrm{~min}$ before or after programmes intended for children younger than 12 years of age ${ }^{(24)}$. Product placements are prohibited in programmes intended for children, but allowed with restrictions in other programmes.

\section{Coding process}

All verbal and visual appearances of foods and beverages were coded. Food appearances included all kinds of foods, beverages or meals that people might be expected to consume. Food appearances were coded into 114 categories (of the original 145 categories developed for previous study ${ }^{(22)}$ and on the basis of each programme, i.e. the same food could appear more than once in each programme but was only coded once.

Only foods that might be associated with people or human-like characters were coded. Thus, grass or insects eaten by animals were not coded. Foods that were a part of the background landscape were not coded (e.g. fruits on trees in the background, fish in sea/lake) unless they were explicit or discussed in terms of food. The coding process is further described in a previous study ${ }^{(22)}$.

Furthermore, each food appearance was coded according to:

1. Display. Categories included whether the food appearance should be coded as verbal (someone mentioning a food item), visual (food item showing) or both.

2. Representation. Categories assessed whether the food appeared passive in the background, passive but explicit (i.e. no one was holding or talking about the food even though it was quite central), whether someone was handling the food (hold, give, get, buy, cook, crave) or eating/drinking the food in question.

3. Age and gender. Two variables assessed the age (child/ teenager or adult) and gender of the characters appearing with the food. It was also noted if the food appeared with both age groups or both genders or without character context.

4. Message. Messages on health (healthy or unhealthy) or taste (palatable or unpalatable) were coded if clearly identified with the food.

Descriptions and comments were written for each of the food appearances. Explicit messages on the food or beverage being palatable or unpalatable were identified, categorized 
and described. These were verbal messages or identified in other ways or clearly expressed, through e.g. a sigh when eating or drinking. Also, verbal messages on the food or beverage being positive or negative for health and well-being were identified, categorized and described. All analyses were performed by the first author based on discussions with the second author and the extensive framework for analyses constructed by both authors for a previous study ${ }^{(22)}$.

\section{Analyses}

The initial 145 categories of food appearances were further aggregated into twenty-three food groups. Two food groups, which could be of special interest from a public health perspective, were analysed further.

1. Fruits and vegetables (F\&V): fruit, berries, vegetables, legumes, root vegetables, juice.

2. High-calorie and low-(micro)nutrient (HCLN) foods, i.e. foods that contribute to energy intake but hardly to intake of vitamins and minerals: cookies, confectionery, sweet beverages, desserts, jam, ice cream, sugar, snacks, alcohol.

The $\chi^{2}$ test was performed to analyse if the occurrence of F\&V and HCLN foods, respectively, was associated with the context where food appeared. All variables were also simultaneously adjusted for each other in two logistic regression models with the appearance of HCLN foods (HCLN $v$. all other foods) and F\&V (F\&V $v$. all other foods), respectively, as dependent variables. A probability value of less than $5 \%$ was considered as statistically significant. Coding and analyses were performed with the statistical software package IBM SPSS Statistics version 22.

\section{Results}

\section{Foods displayed}

Of the 125 different programmes, $85.6 \%$ ( $n$ 107) included a food or beverage. A total of 599 food appearances were counted in the 107 programmes, a mean of 5.6 unique food appearances per programme, and a mean of 22.2 food appearances per hour. When aggregated into twentythree food groups (Fig. 1), the most frequent food group was fruits and berries (14.7\%), followed by mixed meals (all kinds of meals, also fast-food meals; $9.5 \%$ ) and sharing the third place were vegetables ( $8 \%$ ) and cookies and pastry ( $8 \%$ ). Bread and cereals were the fourth most frequent food group, with forty-three appearances accounting for $7 \cdot 2 \%$ of the appearances. Within this group are all kinds of bread accompanied with morning cereals, which are a diverse group of foods ranging from muesli to chocolate puffs. The food groups coffee and tea (6.0\%), meat (5.7\%) and candy (5.2\%) also appeared rather frequently. The programmes were produced in different countries, $28 \%$ in Iceland (mostly the Sunday programme) and $27 \%$ in USA, $16 \%$ in the UK and $12 \%$ in Canada.

\section{Contexts in which foods/beverages were displayed}

Table 1 shows the context in which the foods/beverages were shown or discussed. Food was most often presented together with people, especially adults and/or males. Food was presented with adults more often than children (59\% of the 446 cases when it was obvious that food occurred solely together with adults or children; $P<0 \cdot 001$ ). Food was also presented with males more often than females ( $71 \%$ of the 410 cases when it was obvious that food occurred solely together with females or males; $P<0 \cdot 001$ ).

In total, HCLN foods accounted for $25.5 \%$ of the total food appearances and $\mathrm{F} \& \mathrm{~V}$ for $22.7 \%$. Other foods appeared in $51.8 \%$ of food appearances in the watched material. These were foods other than F\&V or HCLN foods, e.g. bread and cereals, coffee and tea, meat, fish, milk and cheese. How the three food groups appeared within different contexts is shown in Table 2. Both HCLN foods and $\mathrm{F} \& \mathrm{~V}$ were frequent in animated programmes (respectively 26.5 and $26.9 \%$ of the shown foods in animated programmes) and in programmes produced in countries outside the Nordic countries (HCLN foods $28.9 \%$, F\&V 26.2\%).

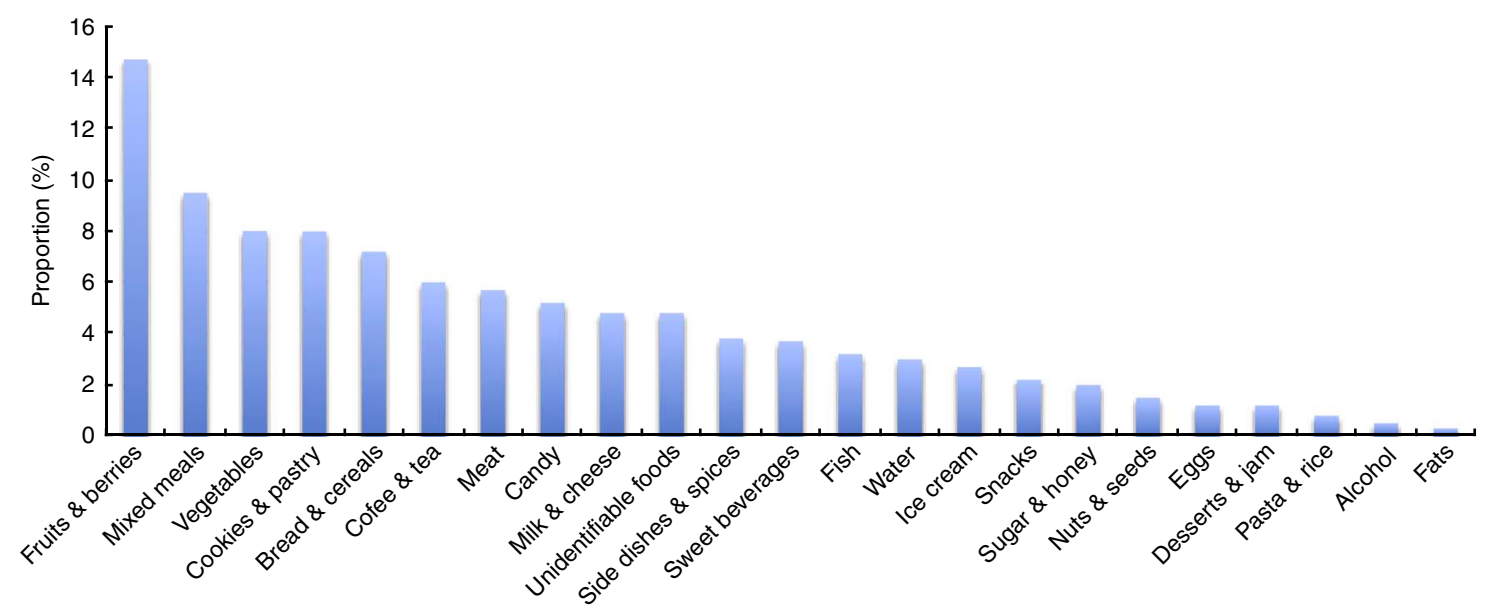

Fig. 1 Proportion of appearance of twenty-three groups of foods in the analysis of $27 \mathrm{~h}$ of children's programmes on Icelandic public service television (RÚV), October 2013-April 2014 and March 2015-February 2016, excluding Christmas, Easter and summer 
Table 1 Food and beverage appearances ( $n$ 599) by programme, type, display, representation, gender and age in the analysis of $27 \mathrm{~h}$ of children's programmes on Icelandic public service television (RÚV), October 2013-April 2014 and March 2015-February 2016 excluding Christmas, Easter and summer

\begin{tabular}{|c|c|c|}
\hline & $n$ & $\%$ \\
\hline \multicolumn{3}{|l|}{ Programme } \\
\hline Icelandic Sunday programme & 163 & 27 \\
\hline Films and cartoons & 436 & 73 \\
\hline \multicolumn{3}{|l|}{ Type } \\
\hline Cartoon/animated & 424 & 69 \\
\hline Not animated & 157 & 26 \\
\hline Both (animated and not) & 34 & 6 \\
\hline \multicolumn{3}{|l|}{ Production } \\
\hline From the Nordic countries & 198 & 33 \\
\hline From the USA & 162 & 27 \\
\hline From the UK and Canada & 179 & 30 \\
\hline Other & 60 & 10 \\
\hline \multicolumn{3}{|l|}{ Display } \\
\hline Verbal & 151 & 25 \\
\hline Visual & 301 & 50 \\
\hline Both & 147 & 25 \\
\hline \multicolumn{3}{|l|}{ Representation } \\
\hline Passive - background & 158 & 26 \\
\hline Passive - explicit & 123 & 21 \\
\hline Handle/crave & 189 & 32 \\
\hline Eat/drink & 129 & 22 \\
\hline \multicolumn{3}{|l|}{ People } \\
\hline With somebody & 590 & 98 \\
\hline With nobody & 9 & 2 \\
\hline \multicolumn{3}{|l|}{ Age } \\
\hline Child(ren) & 183 & 31 \\
\hline Adult(s) & 263 & 44 \\
\hline Both & 73 & 12 \\
\hline Unable to determine & 71 & 12 \\
\hline \multicolumn{3}{|l|}{ Gender } \\
\hline Female(s) & 119 & 20 \\
\hline Male(s) & 291 & 49 \\
\hline Both & 149 & 25 \\
\hline Unable to determine & 31 & - \\
\hline
\end{tabular}

Talking about F\&V was not frequent (11.3\%) compared with the proportion of the visual appearances of $F \& V$ in the programmes (25.6\%). HCLN foods frequently appeared in active situations (consumed or craved for) as $29.9 \%$ of the foods appearing in active situations were HCLN foods. Of the foods appearing with child characters in the programmes, $37.2 \%$ were HCLN foods. No significant gender differences between the different food groups were observed (Table 2).

In a logistic model with all variables in Table 2, HCLN foods were significantly more likely to appear with child characters than other foods and more likely to be verbally referred to. In contrast, F\&V were significantly less likely to be verbally referred to, compared with other foods. No other associations were significant in the two full logistic models.

\section{Messages on health or taste}

Different messages appeared with some of the foods and beverages. Health messages were present in $3.5 \%$ of all food appearances ( $n$ 21), i.e. certain foods were represented as good or bad for the health. The majority mediated a healthy aspect ( $n$ 15) and about half of them were
Table 2 Different contexts in which foods and beverages appeared by food group in the analysis of $27 \mathrm{~h}$ of children's programmes on Icelandic public service television (RÚV), October 2013-April 2014 and March 2015-February 2016, excluding Christmas, Easter and summer

\begin{tabular}{|c|c|c|c|c|c|}
\hline & $\begin{array}{c}\mathrm{HCLN}^{*} \\
(\%)\end{array}$ & $\begin{array}{c}\mathrm{F} \& \mathrm{~V} \dagger \\
(\%)\end{array}$ & $\begin{array}{c}\text { Other } \\
(\%)\end{array}$ & $P \ddagger$ & $P \S$ \\
\hline Total $(n$ 599) & 25.5 & 22.7 & 51.8 & - & - \\
\hline \multicolumn{6}{|l|}{ Type\| } \\
\hline Animated ( $n$ 424) & $26 \cdot 5$ & $26 \cdot 9$ & $46 \cdot 6$ & & \\
\hline Not animated $(n 157)$ & $19 \cdot 0$ & 14.4 & $66 \cdot 7$ & $<0.001$ & NS \\
\hline \multicolumn{6}{|l|}{ Production } \\
\hline Nordic countries ( $n$ 198) & $18 \cdot 7$ & $15 \cdot 7$ & 65.7 & & \\
\hline Other ( $n$ 401) & 28.9 & $26 \cdot 2$ & 44.9 & $<0.001$ & NS \\
\hline \multicolumn{6}{|l|}{ Display } \\
\hline Verbal $(n 151)$ & 29.1 & $11 \cdot 3$ & $59 \cdot 6$ & & \\
\hline Visual ( $n$ 301) & 24.6 & $25 \cdot 6$ & 49.8 & $<0.01$ & $<0.01$ \\
\hline \multicolumn{6}{|l|}{ Representation } \\
\hline Passive ( $n$ 281) & 20.6 & 24.2 & $55 \cdot 2$ & & \\
\hline Active ( $n 318$ ) & 29.9 & 21.4 & 48.7 & $<0.05$ & NS \\
\hline \multicolumn{6}{|l|}{ Gender\| } \\
\hline With female(s) $(n 119)$ & 23.5 & 24.4 & $52 \cdot 1$ & & \\
\hline With male(s) (n 291) & 26.8 & $20 \cdot 3$ & $52 \cdot 9$ & NS & NS \\
\hline \multicolumn{6}{|l|}{ Age $\|$} \\
\hline With child(ren) $(n$ 183) & $37 \cdot 2$ & $22 \cdot 4$ & 40.4 & & \\
\hline With adult(s) (n 263) & $17 \cdot \overline{1}$ & 24.0 & 58.9 & $<0.001$ & $<0.01$ \\
\hline
\end{tabular}

*HCLN, high-calorie and low-nutrient foods (foods that contribute to energy intake but hardly to intake of vitamins and minerals; i.e. cookies, confectionery, sweet beverages, desserts, jam, ice cream, sugar, snacks, alcohol).

†F\&V, fruits and vegetables (fruit, berries, vegetables, legumes, root vegetables, juice).

fFrom $x^{2}$ tests of occurrence of the three groups of foods in different contexts.

§From $x^{2}$ tests of occurrence of F\&V $v$. HCLN in different contexts.

$\|$ Variation in $n$ is due to dichotomization of variables in each context where the categories 'both' or 'unable to determine' (see Table 1) were excluded from the contexts.

for fruits/vegetables being healthy for the body ( $n$ 7). However, one health message was for HCLN foods; a character encouraged another character to drink lemonade soda, as she needed a beverage for good hydration. Messages on negative health influence of certain foods totalled six, or about $1 \%$ of all food appearances, all for HCLN foods. Three were for the importance of good dental care; not eating sugary foods or candy. The fourth was for not eating snacks between meals, the fifth was for not eating too much cake because of risk of stomach ache, and the sixth was a joke encouraging characters to dance, as there were parasites in the muffins they had just eaten.

Taste messages were present in $8 \%$ of all food appearances, mostly indicating palatability ( $n$ 42). In eighteen cases the message of good taste was for HCLN foods: cookies, ice cream, candy and sweet beverages, and in four cases it was for $\mathrm{F} \& \mathrm{~V}$ : apples, strawberries, potatoes and lemons. Six negative taste messages were found in the food appearances, all for foods other than HCLN foods or F\&V (fish, fats, meat, cheese and spices).

\section{Discussion}

In the present study, the nature and extent of verbal and visual food appearances in Icelandic public service 
television were examined. Food was quite prominent in the coded children's programmes broadcast in Iceland, produced in various countries. A mean of 5.6 unique food appearances per programme were coded. The most frequently appearing food group were fruits and berries (14.7\% of appearances). Vegetables appeared less often than fruits and berries, with the same frequency as cookies and pastry ( $8 \%$ ). This is not in line with our previous study performed in Sweden ${ }^{(22)}$, where vegetables were the second most frequently appearing food group (18\%), more than double the appearances of cookies and pastry (7\%). In the current study, other sugar-rich foods like candy and sweetened beverages appeared rather frequently ( 5.2 and $3.7 \%$, respectively), whereas the proportion of those foods in the study performed in Sweden was lower (2.6 and $2.5 \%$, respectively). In total, HCLN foods accounted for $25.5 \%$ of the total food appearances in the current study, compared with $19 \%$ in the previous study. F\&V accounted for $22.7 \%$ of the total food appearances in the current study, compared with $39 \%$ in the previous study. The reasons for these differences might be a small proportion of HCLN foods in the Swedish studio section in the previous study ${ }^{(22)}$, as well as the frequent appearance of a fruit bowl in the Swedish studio sections. This appeared as a deliberate visualization of healthy foods in the Swedish study, whereas similar visualization was not to be found in the Icelandic data. The difference might however also be due to different samples.

HCLN foods were more often talked about than F\&V that were more often shown. This is in line with a study of popular children's books where sweets and cookies were more likely to be portrayed centrally than fruits/vegetables $^{(14)}$. The difference between HCLN foods and F\&V in this sense was also significant in the previous study on children's television programmes in Sweden ${ }^{(22)}$, where HCLN foods were more often presented in active situations than passive in comparison with F\&V. The food appearances may not be explicit messages for the viewers but the context is important for how the content might be interpreted. Mixed messages are not suitable for young children; if they like the cartoon characters, they seem to like the food that is appearing with them, healthy or unhealthy ${ }^{(25)}$. The present study, in the light of our previous and other studies, demonstrates an opportunity for health promotion via public service television channels.

Food content in children's programmes might affect the viewers in various ways. HCLN foods appeared proportionally more often with children than the other food groups, and $59 \%$ of the appearances of HCLN foods were with child characters. This might strengthen the status of HCLN foods and the idea of HCLN foods as appropriate for children. Children can develop friendships with characters on screen, so-called parasocial relationship formation $^{(25)}$. After some time watching a certain programme, a child can get familiar with the characters. This can resemble a real friendship as there is an interaction when the character talks to the audience, encourages to sing along, etc. Even though the present paper does not study the viewer, it is however possible to speculate on the effects of a popular character from a television programme promoting vegetables instead of cookies and pastry. It is beyond dispute that advertisements for HCLN foods affect the viewers ${ }^{(8,9,11)}$. Moreover, using the same kind of marketing techniques for marketing vegetables towards children and adolescents has been found effective for increased consumption ${ }^{(26)}$. An experimental study on the brand of the Icelandic children's television programme LazyTown, which has a focus on healthy lifestyle ${ }^{(27)}$ (not a part of the sample in the present study), found that children perceived food to taste better with the LazyTown label on the wrapping compared with the original wrapping. Healthy foods are rarely marketed to children. However, child-oriented marketing seems to be effective and possible to promote healthy eating among young children.

The different food groups appeared together with males and females to the same extent. However, foods in general were more often displayed with male characters than female characters, as we found in the Swedish study ${ }^{(22)}$ and has been documented previously ${ }^{(28)}$. Aubrey and Harrison $^{(29)}$ found that male cartoon characters were more frequently eating than female characters when appearing on screen. This also reflects that males appear in general more often than females on television, the ratio for children's shows is 2.25 males to 1 female, according to a report from the Geena Davis Institute on Gender in Media $^{(30)}$. This imbalance might also reflect absence of food in the appearance of female characters and thus reinforce the female beauty ideal mediated by television $^{(31,32)}$.

The strengths of the current study are its novelty in an Icelandic context and a possible comparison with a previous study performed in Sweden. The coded material was diverse and aired over a period of different seasons, weekdays and weekends. The different periods are also a limitation of the study; whereas part of the material was aired in 2013-2014, the other part was aired in 2015-2016. The content might have changed since 2013 and not reflect the most recent situation. Another limitation is that the present paper does not study the effects on the viewer, as the analysed material is solely the television programmes with no data from viewers.

There was no separation of television programmes for younger children or older children in the current study. The productions or the television channel do not identify the viewer group of the programmes included, and the assumption is that they are for viewers approximately up to 10 years of age. Other studies have focused on tween programmes and found a high prevalence of appearances of non-nutritious foods in such programmes ${ }^{(17)}$ especially fast foods and sugar-sweetened beverages ${ }^{(18)}$, as well as 
portrayals of snacking ${ }^{(20)}$ and brand appearances ${ }^{(33)}$. The present study has further found that unhealthy foods are also presented favourably, i.e. HCLN foods were represented as desirable for children by appearing more often together with children than other foods. There is a need for analysing all kinds of television programmes intended for children and adolescents, not least the youngest children, as this is a critical period for founding healthy habits for later in life.

A large part of the programmes is broadcast in various countries, and the results from Northern Europe presented here and in our previous study might be of interest for other parts of the world. Our results show that HCLN foods appeared even more frequently in programmes produced outside the Nordic countries than in productions from the Nordic countries. Even if the studies already performed in Europe and the USA on how food is presented in children's television programmes are not comparable in methodology as the unit of analysis is not the same (time slots, scenes, programmes), the conclusions however point in the same direction: that there is room for action regarding the depiction of healthy foods in television programmes ${ }^{(20,22,28)}$ where the healthy foods could as well be portrayed as desirable, appropriate for celebrating, tasty, fun and positive. The content of television programmes with regard to portraying different foods deserves the attention of producers and buyers of children's television programmes, as well as parents, researchers, teachers and health professionals.

\section{Conclusions}

The main conclusion of the present study is that public service television has the potential to improve the way food and eating is depicted. HCLN foods accounted for one-quarter of the total food appearances in the programmes, which was slightly more frequent than for F\&V together. The contexts in which different food groups were displayed were similar to those found in a previous Swedish study: HCLN foods were presented together with child rather than adult characters, and were presented verbally to a greater extent, compared with the F\&V food group.

\section{Acknowledgements}

Financial support: This work was supported by the Icelandic Public Health Fund (grant number P-2014-02-27-0027). The funder had no role in the design, analysis or writing of this article. Conflict of interest: None. Authorship: S.O. and C.B. designed the study. S.O. carried out the analyses and wrote the first draft. Both authors contributed to the final version. Ethics of human subject participation: Not applicable.

\section{References}

1. Matthiessen J, Andersen L, Barbieri H et al. (2017) Status and Development of Diet, Physical Activity, Smoking, Alcohol and Overweight. Copenhagen: Nordic Council of Ministers.

2. Boynton-Jarrett R, Thomas T, Peterson $\mathrm{K}$ et al. (2003) Impact of television viewing patterns on fruit and vegetable consumption among adolescents. Pediatrics 112, 1321-1326.

3. Wiecha J, Peterson K, Ludwig D et al. (2006) When children eat what they watch: impact of television viewing on dietary intake in youth. Arch Pediatr Adolesc Med 160, 436-442.

4. Barr-Anderson DJ, Larson NI, Nelson MC et al. (2009) Does television viewing predict dietary intake five years later in high school students and young adults? Int J Behav Nutr Phys Act 6, 7.

5. Hare-Bruun H, Nielsen BM, Kristensen PL et al. (2011) Television viewing, food preferences, and food habits among children: a prospective epidemiological study. $B M C$ Public Health 11, 311.

6. Pearson N, Ball K \& Crawford D (2011) Mediators of longitudinal associations between television viewing and eating behaviours in adolescents. Int J Behav Nutr Phys Act 8, 23.

7. Olafsdottir S, Berg C, Eiben G et al. (2014) Young children's screen activities, sweet drink consumption and anthropometry: results from a prospective European study. Eur J Clin Nutr 68, 223-228.

8. Cairns G, Angus K \& Hastings G (2009) The Extent, Nature and Effects of Food Promotion to Children: A Review of the Evidence to December 2008. Geneva: WHO.

9. Kelly B, Halford JCG, Boyland EJ et al. (2010) Television food advertising to children: a global perspective. Am J Public Health 100, 1730-1736.

10. Boyland E, Nolan S, Kelly B et al. (2016) Advertising as a cue to consume: a systematic review and meta-analysis of the effects of acute exposure to unhealthy food and nonalcoholic beverage advertising on intake in children and adults. Am J Clin Nutr 103, 519-533.

11. Norman J, Kelly B, Boyland E et al. (2016) The impact of marketing and advertising on food behaviours: evaluating the evidence for a causal relationship. Curr Nutr Rep $\mathbf{5}$, 139-149.

12. Olafsdottir S, Eiben G, Prell H et al. (2014) Young children's screen habits are associated with consumption of sweetened beverages independently of parental norms. Int J Public Health 59, 67-75.

13. Folkvord F, Anschütz DJ, Boyland E et al. (2016) Food advertising and eating behavior in children. Curr Opin Behav Sci 9, 26-31.

14. Goldman JE \& Descartes L (2016) Food depictions in picture books for preschool children: frequency, centrality, and affect. Appetite 96, 203-208.

15. NORDICOM (n.d.) Mediestatistik. http://www.nordicom.gu. se/sv/mediefakta/mediestatistik (accessed July 2016).

16. Gallup (n.d.) Sjónvarp (Television). http://www.gallup.is/ nidurstodur/sjonvarp/ (accessed January 2017).

17. Roseman M, Poor M \& Stephenson T (2014) A content analysis of food references in television programming specifically targeting viewing audiences aged 11 to 14 years. J Nutr Educ Behav 46, 20-25.

18. Scully P, Reid O, Macken A et al. (2016) Food and beverage cues in children's television programmes: the influence of programme genre. Public Health Nutr 19, 616-624.

19. Greenberg BS, Rosaen SF, Worell TR et al. (2009) A portrait of food and drink in commercial TV series. Health Commun 24, 295-303.

20. Eisenberg M, Larson N, Gollust S et al. (2016) Snacking on television: a content analysis of adolescents' favorite shows. Prev Chronic Dis 13, E66. 
21. Radnitz C, Byrne S, Goldman R et al. (2008) Food cues in children's television programs. Appetite 52, 230-233.

22. Olafsdottir S \& Berg C (2016) Food appearances in children's television programmes in Sweden. Int J Consum Stud 40, 484-491.

23. Icelandic Parliament (2013) Act on the Icelandic National Broadcasting Service, a public service medium (Lög um Rikisútvarpið, fjölmiðil 1 almannapágu, nr. 23/2013). https://www. althingi.is/altext/stit/2013.023.html (accessed September 2016).

24. Icelandic Parliament (2011) Media Law no. 38/2011. http://www.althingi.is/lagas/nuna/2011038.html (accessed September 2016).

25. Buijzen M, Rozendaal E \& de Droog SM (2014) Food marketing and child health. In Young People, Media and Health: Risks and Rights, pp. 121-128 [C von Feilitzen and J Stenersen, editors]. Gothenburg: International Clearinghouse on Children, Youth and Media/NORDICOM.

26. Hanks A, Just D \& Brumberg A (2016) Marketing vegetables in elementary school cafeterias to increase uptake. Pediatrics 138, e20151720.

27. Gunnarsdottir I \& Thorsdottir I (2010) Should we use popular brands to promote healthy eating among children? Public Health Nutr 13, 2064-2067.
28. Scully P, Reid O, Macken A et al. (2014) Food and beverage cues in UK and Irish children - television programming. Arch Dis Child 99, 979-984.

29. Aubrey JS \& Harrison K (2004) The gender-role content of children's favorite television programs and its links to their gender-related perceptions. Media Psychol 6, 111-146.

30. Smith SL, Choueiti M, Prescott A et al. (2012) Gender Roles and Occupations: A Look at Character Attributes and Job-Related Aspirations in Film and Television. Los Angeles, CA: Geena Davis Institute on Gender in Media.

31. Herbozo S, Tantleff-Dunn S, Gokee-Larose J et al. (2004) Beauty and thinness messages in children's media: a content analysis. Eat Disord 12, 21-34.

32. López-Guimera G, Levine MP, Sánchez-Carracedo D et al. (2010) Influence of mass media on body image and eating disordered attitudes and behaviors in females: a review of effects and processes. Media Psychol 13, 387-416.

33. Speers S, Harris J \& Schwartz M (2011) Child and adolescent exposure to food and beverage brand appearances during prime-time television programming. Am J Prev Med 41, 291-296. 